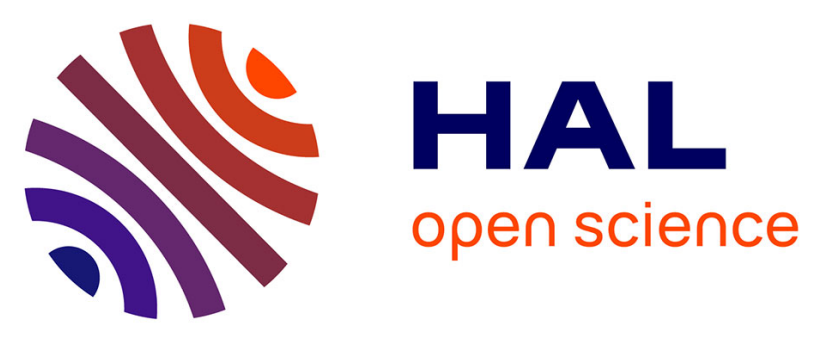

\title{
Mass transfer and residence time distribution in an electrochemical cell with an air-diffusion electrode: Effect of air pressure and mesh promoters
}

\author{
W. Shane Walker, Eliane Bezerra Cavalcanti, Aksana Atrashkevich, Ana S
} Fajardo, Enric Brillas, Sergi Garcia-Segura

\section{To cite this version:}

W. Shane Walker, Eliane Bezerra Cavalcanti, Aksana Atrashkevich, Ana S Fajardo, Enric Brillas, et al.. Mass transfer and residence time distribution in an electrochemical cell with an air-diffusion electrode: Effect of air pressure and mesh promoters. Electrochimica Acta, 2021, 378, pp.138131. 10.1016/j.electacta.2021.138131 . hal-03367494v2

HAL Id: hal-03367494

https://hal.sorbonne-universite.fr/hal-03367494v2

Submitted on 7 Oct 2021

HAL is a multi-disciplinary open access archive for the deposit and dissemination of scientific research documents, whether they are published or not. The documents may come from teaching and research institutions in France or abroad, or from public or private research centers.
L'archive ouverte pluridisciplinaire HAL, est destinée au dépôt et à la diffusion de documents scientifiques de niveau recherche, publiés ou non, émanant des établissements d'enseignement et de recherche français ou étrangers, des laboratoires publics ou privés. 


\section{Mass transfer and residence time distribution in an electrochemical cell with an air-diffusion electrode: effect of air pressure and mesh promoters}

W. Shane Walker ${ }^{\mathrm{a}}$, Eliane Bezerra Cavalcanti ${ }^{\mathrm{b}}$, Aksana Atrashkevich $^{\mathrm{c}}$, Ana S. Fajardo ${ }^{\mathrm{c}, \mathrm{d}, \#, *}$, Enric Brillas ${ }^{\mathrm{e}, \#}$, Sergi Garcia-Segura ${ }^{\mathrm{c}, *, \#}$

${ }^{a}$ Nanosystems Engineering Research Center for Nanotechnology-Enabled Water Treatment, Department of Civil Engineering, Center for Inland Desalination Systems, The University of Texas at El Paso, El Paso, TX, 79968, United States

bInstituto de Tecnologia e Pesquisa/ITP, Universidade Tiradentes/UNIT, Av. Murilo Dantas 300, CEP 49032-490 Aracaju, SE, Brazil

${ }^{\mathrm{c}}$ Nanosystems Engineering Research Center for Nanotechnology-Enabled Water Treatment (NEWT),

School of Sustainable Engineering and the Built Environment, Arizona State University, Tempe, Arizona 85287-3005, United States

${ }^{\mathrm{d}}$ Sorbonne Université, CNRS, Laboratoire Interfaces et Systèmes Electrochimiques (LISE), 4 place Jussieu, F-75005, Paris, France

'Laboratori d'Electroquímica dels Materials i del Medi Ambient, Departament de Química Física, Facultat de Química, Universitat de Barcelona, Martí i Franquès 1-11, 08028 Barcelona, Spain

* Corresponding author: (A.S. Fajardo) adossan3@asu.edu, (S. Garcia-Segura) $\underline{\text { sergio.garcia.segura@asu.edu }}$

\# ISE Active Member 


\begin{abstract}
Electrochemical advanced oxidation processes (EAOPs) have shown excellent capabilities to the abatement of recalcitrant organic pollutants. The Fenton-based electrochemical systems have shown great performance for in-situ generation of $\mathrm{H}_{2} \mathrm{O}_{2}$, allowing an efficient ${ }^{\bullet} \mathrm{OH}$ production for the mineralization of organic pollutants. These systems have been widely applied at bench scale; however, studies to scale-up to a higher technology readiness level (TRL) are lacking. One of the main scale-up challenges of the Fenton-based systems is the implementation of air diffusion electrodes (ADE) in flow-by electrochemical cells. The ADE adds additional complexity with respect to mass transfer effects due to hydraulic reactor design and ADE gas pressure control. Therefore, this work experimentally investigated residence time distribution and platinum-sheet electrode mass transfer effects due to (a) the liquid cross-flow velocity through the electrochemical cell, (b) the gas pressure of the air-diffusion electrode (ADE), and (c) the presence of mesh sheet mass transfer promoters between the electrodes. Analysis of experimental results revealed a synergistic improvement of mass transfer with the ADE gas flow and the presence of mesh promoters. Engineers could exploit this synergistic effect to design electrochemical cells with significantly lower capital cost.
\end{abstract}

Keywords: air-diffusion electrode, electrochemical engineering, advanced oxidation processes, electro-Fenton, water treatment 


\section{Introduction}

The increasing concern of the environmental impact of persistent organic pollutants (POPs) has promoted research and development of eco-sustainable technologies for water treatment. It is generally understood that conventional adsorption, physico-chemical, and biological treatments used in wastewater treatment plants are not highly efficient at removing POPs $[1,2]$. Thus, the development of powerful oxidation methods has been of significant interest in water treatment research during the last decades. In this context, the electrochemical advanced oxidation processes (EAOPs) have received great attention due to their high efficiency, environmental compatibility, versatility, and safety [1-8]. Among the EAOPs, the electro-Fenton (EF) process and its derivatives are of interest because some groundwaters and many domestic wastewaters may contain sufficient iron concentration in situ [6-8]. In EF, hydrogen peroxide $\left(\mathrm{H}_{2} \mathrm{O}_{2}\right)$ is continuously generated and supplied to the polluted solution by the two-electron reduction of $\mathrm{O}_{2}$ at carbonaceous cathodes via reaction (1). This electrogenerated $\mathrm{H}_{2} \mathrm{O}_{2}$ reacts with a catalytic quantity of ferrous ion $\left(\mathrm{Fe}^{2+}\right)$ to yield ferric ion $\left(\mathrm{Fe}^{3+}\right)$ and hydroxyl radical $\left({ }^{\bullet} \mathrm{OH}\right)$ in the solution by Fenton's reaction (2) under acidic conditions (optimum $\mathrm{pH}$ near 3 ) $[1-3,7]$. The ${ }^{\bullet} \mathrm{OH}$ then oxidizes the POPs and can achieve complete mineralization by reaction (3). The $\mathrm{Fe}^{2+}$ acts as catalyst since it can be quickly regenerated by reduction of $\mathrm{Fe}^{3+}$ ion to $\mathrm{Fe}^{2+}$ ion at the cathode [1]

$\mathrm{O}_{2(\mathrm{~g})}+2 \mathrm{H}^{+}+2 \mathrm{e}^{-} \rightarrow \mathrm{H}_{2} \mathrm{O}_{2}$

$\mathrm{H}_{2} \mathrm{O}_{2}+\mathrm{Fe}^{2+} \rightarrow \mathrm{Fe}^{3+}+\cdot \mathrm{OH}+\mathrm{OH}^{-}$

POPs $+\cdot \mathrm{OH} \rightarrow \mathrm{CO}_{2}+\mathrm{H}_{2} \mathrm{O}$

Carbon-polytetrafluoroethylene (PTFE) cloth gas $\left(\mathrm{O}_{2}\right.$ or air) diffusion electrodes (ADEs) have shown great $\mathrm{H}_{2} \mathrm{O}_{2}$ production that allows an efficient ${ }^{\circ} \mathrm{OH}$ generation leading to a quick degradation and mineralization of POPs by EF and related processes [9-13]. This is feasible 
because a 3D ADE ensures a remarkably high efficiency for $\mathrm{O}_{2}$ reduction by reaction (1) since it is not limited by the mass transfer of the gas such as occurs with immersed cathodes that are feed with the dissolved $\mathrm{O}_{2}$ in solution. Among the latter kinds of cathodes, carbon felt [14-18], graphite felt [19,20], graphene felt [21], reticulated vitreous carbon [22,23] and boron-doped diamond (BDD) [24] have shown a good effectiveness to destroy POPs by these procedures. The oxidation ability of EF and related processes also depends on the nature of the anode, which produces heterogeneous ${ }^{\bullet} \mathrm{OH}$ at its surface from water discharge [3]. It has been found that nonactive BDD electrodes are the most powerful anodes, producing higher amounts of heterogeneous ${ }^{\bullet} \mathrm{OH}$ than other materials and favoring the removal of organics, although the homogeneous ${ }^{\bullet} \mathrm{OH}$ formed from reaction (2) is the preferred oxidizing agent $[12,25]$.

While the ADEs have been extensively used at lab scale for wastewater treatment, less is known over their scale-up for possible industrial application. To do this, it is necessary the analysis of the factors influencing the mass transfer of the feeding gas through them to know the optimum operating conditions for achieving the faster $\mathrm{O}_{2}$ reduction.

The present work aims to study the influence of (i) the gas percolating through the ADE and (ii) the presence of different mesh sheet mass transfer promoters between the parallel electrodes on the residence time distribution of the plate-and-frame of a flow-by electrochemical cell, as well as the mass transfer efficiency at an active platinum sheet anode. 


\section{Experimental}

\subsection{Chemicals}

Analytical grade potassium chloride $(\mathrm{KCl})$, potassium ferricyanide $\left(\mathrm{K}_{3} \mathrm{Fe}(\mathrm{CN})_{6}\right)$, potassium ferrocyanide $\left(\mathrm{K}_{4} \mathrm{Fe}(\mathrm{CN})_{6}\right)$, and sodium sulfate $\left(\mathrm{Na}_{2} \mathrm{SO}_{4}\right)$ were supplied by Sigma-Aldrich. All the solutions were prepared with high-purity water obtained from a Millipore Milli-Q system with resistivity $>18.2 \mathrm{M} \Omega \mathrm{cm}$ at $25{ }^{\circ} \mathrm{C}$.

\subsection{Electrochemical cell}

A schematic of the electrolytic cell is shown in Fig. 1 and it consisted of an undivided plateand-frame electrochemical cell equipped with a platinum $(\mathrm{Pt})$ sheet anode from SEMPSA and a carbon-PTFE cloth air-diffusion cathode from E-TEK ${ }^{\circledR}$. The liquid compartment had a central window of $9.5 \mathrm{~cm} \times 9.5 \mathrm{~cm}\left(90.2 \mathrm{~cm}^{2}\right)$, and the electrodes were placed in parallel and separated by an interelectrode gap of $1.2 \mathrm{~cm}$. The inner face of the porous cathode was pressed to a nickel (Ni) mesh as an electrical connector in contact with a PVC gas chamber from which compressed air or nitrogen passed through the cathode to the electrolytic solution. The gas chamber pressure was measured by a manometer. For the experiments without flowing gas, the gas chamber module was replaced by a conventional sealing endplate, while using the same carbon-PTFE cloth as cathode pressed to a Ni mesh plate. In order to evaluate the influence of mesh sheet mass transfer promoters (sandwiched between the electrodes), different arrangements were studied with or without mesh mass transfer promoters ( 

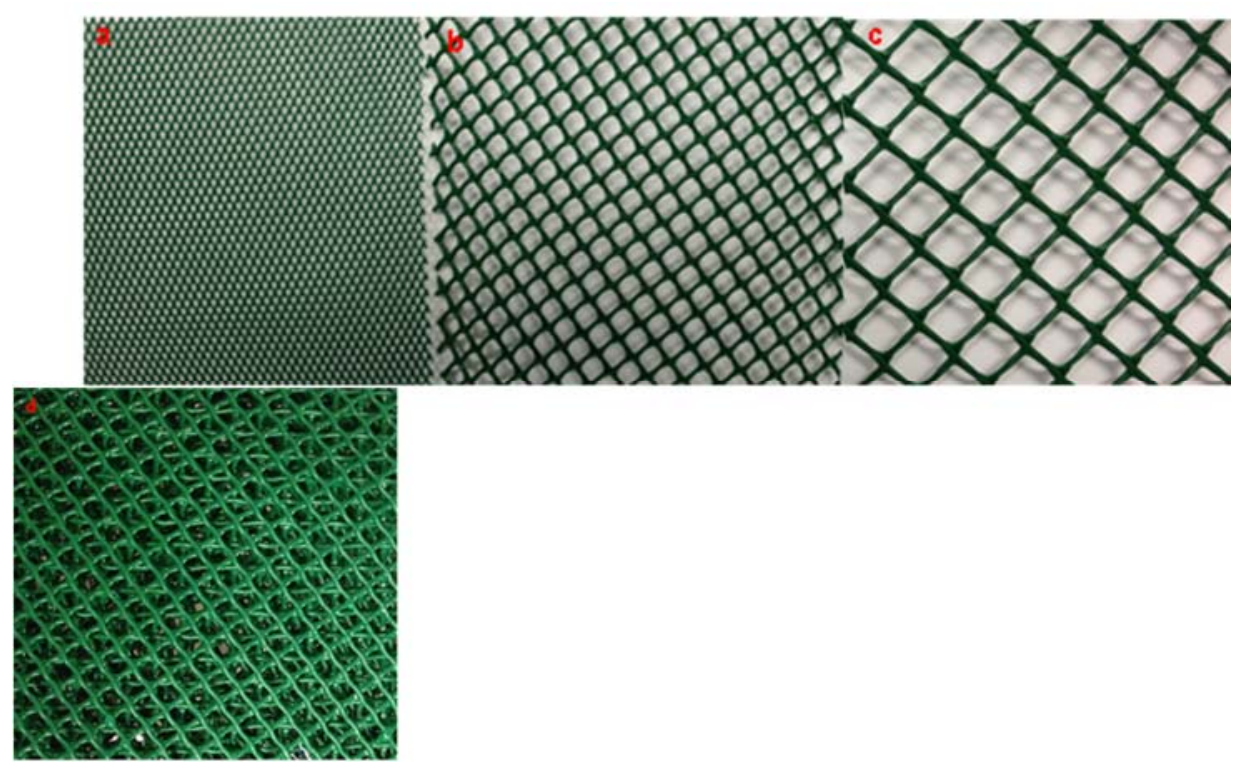

Fig. 2). These promoters consisted of plastic polypropylene mesh sheets of different rhombus sizes, and their characteristics are summarized in Table 1. The water inlet and outlet were placed in the inner plate between electrodes, and water flow was distributed uniformly through 81 holes of $1.5 \mathrm{~mm}$ diameter ( 3 rows of 27 holes each). The solution was continuously recirculated from a $10 \mathrm{~L}$ reservoir to the reactor by a pump at adjustable flow rates, monitored by a rotameter, and the temperature was maintained at $35^{\circ} \mathrm{C}$ by two heat exchangers, as reported elsewhere [9].
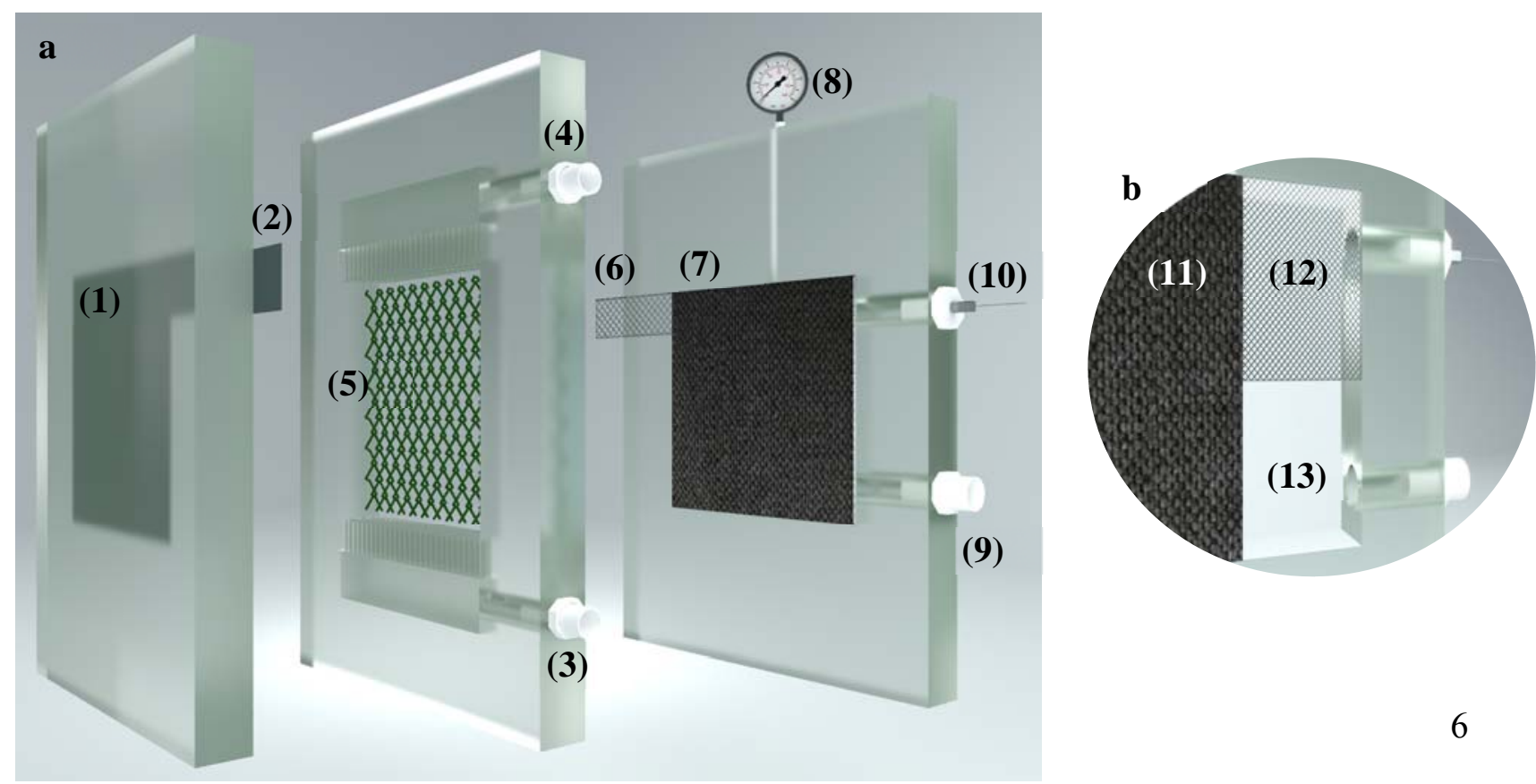


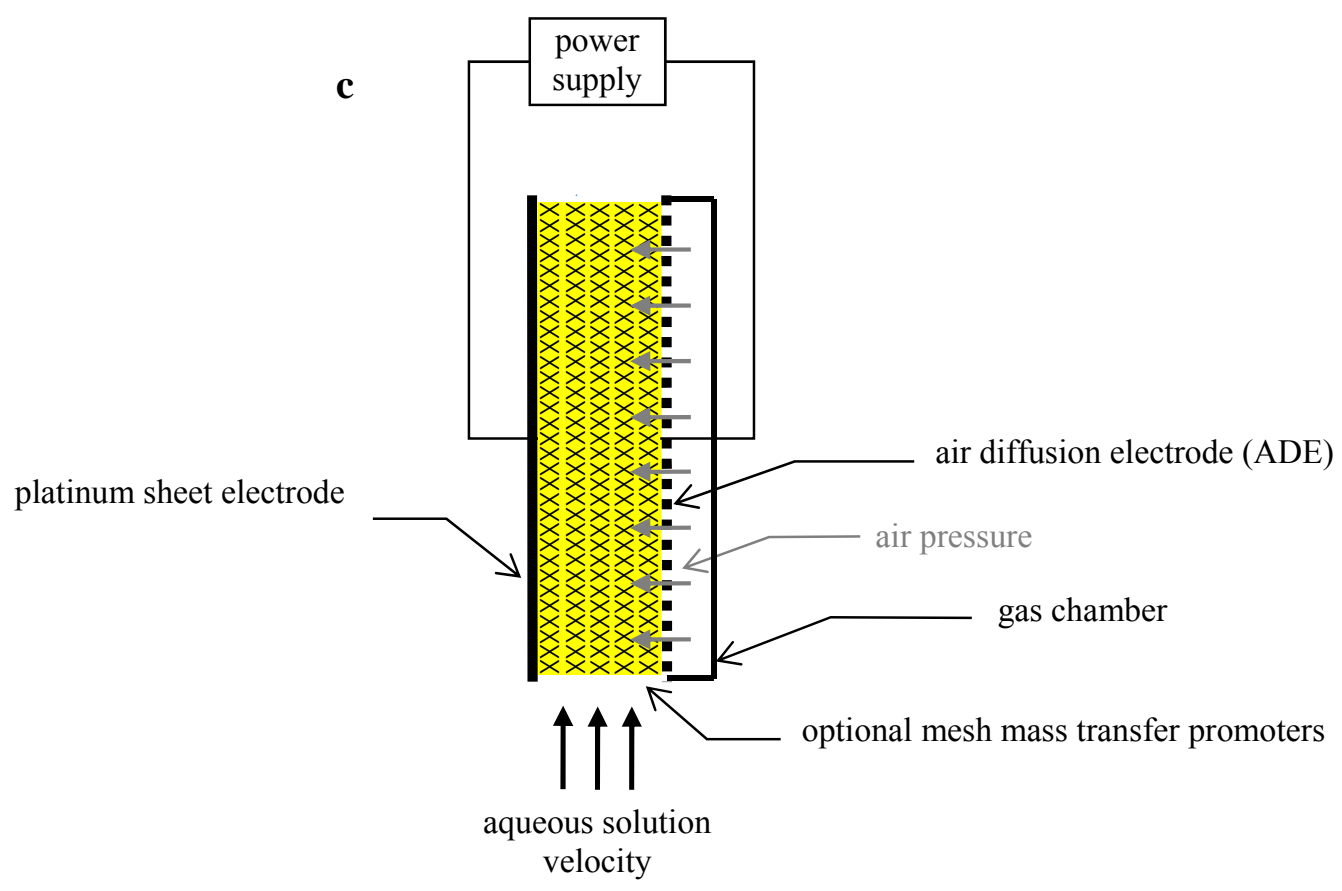

Fig. 1. (a) Sketch of the electrochemical cell reactor: (1) Pt electrode, (2) Pt electrode connector, (3) Solution inlet, (4) Solution outlet, (5) Liquid compartment that contains mesh mass transfer promoters [only one is designed to illustrate better the distributor channel in the cell], (6) ADE electrode connector consisting of a Ni mesh plate, (7) carbon-PTFE cloth of the air diffusion electrode [the gas chamber is located behind the carbon-PTDE cloth sustained on the Ni mesh, (8) manometer to measure the pressure within the gas chamber, (9) gas inlet, (10) gas outlet. (b) Illustration of the air diffusion electrode plate that contains the (11) carbon-PTFE cloth on a (12) Ni mesh as current distributor assembled on the (13) gas chamber compartment. (c) Engineering scheme that illustrates the solution and gas flow within the plate-and-frame electrolytic cell with a platinum sheet anode and an air diffusion electrode (ADE) as the cathode. 


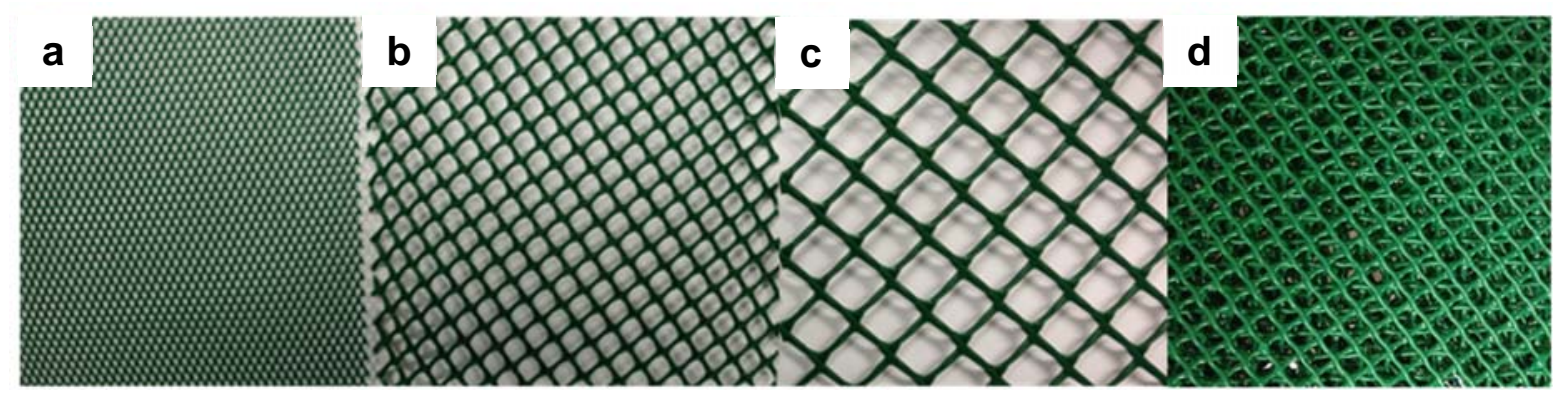

Fig. 2. Mesh mass transfer promoters: (a) small rhombuses size, (b) medium rhombuses size, (c) large rhombuses size, and (d) multiple promoters in crossed distribution into the cell. Scale bars correspond to $1.5 \mathrm{~cm}$.

Table 1. Characteristics and number of mesh sheet mass transfer promoters used in the cell.

\begin{tabular}{ccccccc}
\hline $\begin{array}{c}\text { Parallelogram } \\
\text { size }\end{array}$ & $\begin{array}{c}\text { Aperture } \\
\text { center to } \\
\text { center } \\
(\mathbf{c m})\end{array}$ & $\begin{array}{c}\text { Thickness } \\
\mathbf{( m m )}\end{array}$ & $\begin{array}{c}\text { Volume } \\
\left.\mathbf{( c m}^{\mathbf{3}}\right)\end{array}$ & $\begin{array}{c}\text { Number } \\
\text { used }\end{array}$ & $\begin{array}{c}\text { Total } \\
\text { volume } \\
\left(\mathbf{c m}^{3}\right)\end{array}$ & Porosity \\
\hline Small & 0.3 & 1 & 2 & 10 & 20 & 0.83 \\
Medium & 0.8 & 2 & 4 & 5 & 20 & 0.83 \\
Large & 1.5 & 3 & 3 & 3 & 9 & 0.92 \\
\hline
\end{tabular}

\subsection{Residence time distribution measurement}

Pulse tracer tests were performed to analyze the residence time distribution of the reactor by rapidly injecting a volume of $1 \mathrm{~cm}^{3}$ of a $3.0 \mathrm{~mol} \mathrm{~L}^{-1} \mathrm{KCl}$ solution (i.e., $0.223 \mathrm{~g}$ of $\mathrm{KCl}$ ) into the inlet of the reactor [26,27]. The reactor was continuously fed with deionized water, and the effluent was discarded. The change in solution conductivity was monitored versus time at the 
outlet of the electrolytic cell, and the procedure was repeated with different flow rates, mesh mass transfer promoters, and gas chamber pressures. The potassium chloride concentration $\left(C^{\prime}\right)$ at time $t$ was calculated with Eq. (4), based on the electrical conductance $(G)$ according to a multipoint calibration with $\mathrm{KCl}$ standard solutions. The effective tracer concentration $(C)$ at time $t$ was calculated with Eq. (5) by subtracting the effects of the non-zero background conductance of the reagent water $\left(C^{\prime}{ }_{0}\right)$, given by Eq. (6), where $G_{0}$ was the conductance at $t=0$ (i.e., the instant of tracer injection).

$C^{\prime}=\left[0.41716+0.00308\left(\frac{G}{\mathrm{mS}}\right)\right] \mathrm{mmol} \mathrm{L}^{-1}$

$C=C^{\prime}-C_{0}^{\prime}$

$C^{\prime}{ }_{0}=\left[0.41716+0.00308\left(\frac{G_{0}}{\mathrm{~ms}}\right)\right] \mathrm{mmol} \mathrm{L}^{-1}$

The mean detention time ( $t_{\text {mean }}$ or $\bar{t}$ ), dimensionless time $(\theta)$, normalized pulse tracer concentration $\left(C_{N}\right)$, exit age distribution function $(E(\theta))$, and dimensionless variance of the tracer test with respect to dimensionless time $\left(\sigma_{\theta}^{2}\right)$ were calculated according to the procedure described in Section 6-6 of [27] and are listed here as Eq. (7) through (11), respectively. Replicates of experiments indicate an error of $3 \%$ on the estimation of mean detention time with a standard deviation of $\pm 0.1 \mathrm{~min}$.

$t_{\text {mean }}=\bar{t}=\frac{\int_{0}^{\infty} C t d t}{\int_{0}^{\infty} C d t} \cong \frac{\sum \overline{C t} \Delta t}{\sum \bar{C} \Delta t}$

$\theta=\frac{t}{\bar{t}}$

$C_{N}=\int_{0}^{\infty} C d \theta=\frac{\int_{0}^{\infty} C d t}{\bar{t}} \cong \frac{\sum \bar{C} \Delta t}{\bar{t}}$

$E(\theta)=\frac{C}{C_{N}}$ 
$\sigma_{\theta}^{2}=\int_{0}^{\infty} E(\theta)(\theta-1)^{2} d \theta=\frac{\sigma_{t}^{2}}{\bar{t}^{2}}=\frac{\left(\frac{\int_{0}^{\infty}(t-\bar{t})^{2} C d t}{\int_{0}^{\infty} C d t}\right)}{\bar{t}^{2}} \cong \frac{\left(\frac{\Sigma(t-\bar{t})^{2} C}{\Sigma \bar{C} \Delta t}\right)}{\bar{t}^{2}}$

The dimensionless dispersion number $d$ (i.e., the reciprocal of the Peclet number, Pe) [28] was calculated for the dispersed flow model (DFM, i.e., a plug flow reactor with dispersion) with closed and open boundaries based on the dimensionless variance $\left(\sigma_{\theta}^{2}\right)$ according to Eq. (12) (corresponding to Eq. 6-100 in Section 6-7 of [27]) and Eq. (13) (corresponding to Eq. 2-81 in Section 2.4 of [26]), respectively:

$2 d_{\text {closed }}-2 d_{\text {closed }}^{2}\left(1-e^{\frac{-1}{d_{\text {closed }}}}\right)=\sigma_{\theta}^{2}$

$\frac{2 d_{\text {open }}+8 d_{\text {open }}^{2}}{\left(1+2 d_{\text {open }}\right)^{2}}=\sigma_{\theta}^{2}$

The actual dispersion number for each hydraulic condition is likely bounded between these two dispersion number values, and the range between the closed and open dispersion values is an indicator of the uncertainty of the estimation of dispersion.

\subsection{Mass transfer measurement}

Linear sweep voltammetry analysis was conducted with an Ecochemie Autolab PGSTAT100 potentiostat-galvanostat controlled by an Autolab Nova 1.5 software. The measurements were performed with a three-electrode system using a Haber-Luggin capillary probe in the reactor at the middle region with a $\mathrm{Ag} / \mathrm{AgCl} / \mathrm{KCl}_{\text {(saturated) }}$ reference electrode $\left(\mathrm{E}^{\circ}=0.197 \mathrm{~V} / \mathrm{SHE}\right)$. The $\mathrm{Pt}$ sheet acted as the working electrode (cathode), and the C-PTFE ADE electrode acted as the counter electrode (anode) for the mass transfer characterization.

The water reservoir of the experimental system was filled with $8 \mathrm{~L}$ of a ferricyanideferrocyanide solution composed of $15 \mathrm{mmol} \mathrm{L}^{-1}$ of $\mathrm{K}_{3} \mathrm{Fe}(\mathrm{CN})_{6}$ and $25 \mathrm{mmol} \mathrm{L}^{-1}$ of $\mathrm{K}_{4} \mathrm{Fe}(\mathrm{CN})_{6}$, 
along with 50 mmol L-1 of $\mathrm{Na}_{2} \mathrm{SO}_{4}$ as supporting electrolyte. The test reaction was the electrochemical reduction of ferricyanide at the platinum electrode as described by Eq. (14). Note that the ferrocyanide concentration was 1.67 times that of the ferricyanide to ensure that the limiting reaction would be the reduction of ferricyanide ion at the platinum electrode since the geometric areas of the electrodes are the same in this case.

$\left[\mathrm{Fe}(\mathrm{CN})_{6}\right]^{3-}+\mathrm{e}^{-} \rightarrow\left[\mathrm{Fe}(\mathrm{CN})_{6}\right]^{4-}$

The solution was maintained at $35^{\circ} \mathrm{C}$ and recirculated through the system at different flow rates with or without mass transfer promoters, as well as evaluating the influence of the gas pressure in the gas chamber of the ADE. The solution properties at $35^{\circ} \mathrm{C}$ are listed in Table 2 [29]. To avoid the oxidation of ferrocyanide by dissolved oxygen, the water was degassed with nitrogen for 30 min prior to experimentation, and this gas was also fed into the ADE gas chamber.

Table 2. Physical-chemical mass transfer characteristics of the ferrocyanide-ferricyanide solution at $35{ }^{\circ} \mathrm{C}[29]$.

\begin{tabular}{ll}
\hline Characteristic & Value \\
Density, specific mass $(\rho)$ & $1077 \mathrm{~kg} \mathrm{~m}^{-3}$ \\
Dynamic viscosity $(\mu)$ & $1.287 \times 10^{-3} \mathrm{~kg} \mathrm{~m}^{-1} \mathrm{~s}^{-1}$ \\
Kinematic viscosity $(v)$ & $1.195 \times 10^{-6} \mathrm{~m}^{2} \mathrm{~s}^{-1}$ \\
Diffusion coefficient of $\mathrm{Fe}(\mathrm{CN}) 6^{3-}(D)$ & $6.4 \times 10^{-10} \mathrm{~m}^{2} \mathrm{~s}^{-1}$ \\
Schmidt number $(\mathrm{Sc})$ & 1740 \\
\hline
\end{tabular}

The global mass transfer coefficients $\left(k_{\mathrm{m}}\right)$ were calculated from Eq. (15) [30]:

$k_{m}=\frac{I_{l i m}}{z F A_{e} C_{\infty}}$ 
where $I_{\lim }$ is the limiting current (A), $z$ is the number of electrons involved in the ferricyanide reduction (i.e., $1 \mathrm{eq} \mathrm{mol}^{-1}$ ) from Eq. (4), $F$ is the Faraday constant $\left(96,485.3 \mathrm{C} \mathrm{eq}^{-1}\right), A_{\mathrm{e}}$ is the exposed platinum electrode area $\left(90.25 \mathrm{~cm}^{2}\right)$, and $C_{\infty}$ is the bulk ferricyanide concentration of 15 mmol L ${ }^{-1}$. With the experimentally determined $k_{\mathrm{m}}$ values, the dimensionless Sherwood number (Sh) was obtained by Eq. (16) [31]:

$\mathrm{Sh}=\frac{k_{m} d_{h y d}}{D_{\left[\mathrm{Fe}(\mathrm{CN})_{6}\right]^{3-}}}$

where $D_{\left[\mathrm{Fe}(\mathrm{CN})_{6}\right]^{3-}}$ is the molecular diffusion coefficient (diffusivity) of ferricyanide (Table 2), and $d_{\text {hyd }}$ is the equivalent hydraulic diameter $(0.0213 \mathrm{~m})$, which is a function of the breadth of the channel $(B)$ of $0.095 \mathrm{~m}$ and the interelectrode distance in the cell $(S)$ of $0.012 \mathrm{~m}$, as shown in Eq. (17) [31]:

$d_{h y d}=\frac{4 B S}{2 B+2 S}$

The Sherwood number can be correlated with flow conditions from Eq. (18) [27,32]:

$\mathrm{Sh}=a \operatorname{Re}^{b} \mathrm{Sc}^{c}$

where the empirical $a, b$, and $c$ coefficients are determined from the correlation between calculated values of Sherwood number, Reynolds number (Re), and Schmidt (Sc) number (a constant value of 1740 in these experiments). The Reynolds number is a function of the density $(\rho)$ of the solution, the hydraulic diameter of the flow path (defined above), the mean liquid cross-flow velocity ( $v_{\text {avg }}$ ), and the dynamic viscosity $(\mu)$, according to Eq. (19) [33]:

$\operatorname{Re}=\frac{\rho d_{\text {hyd }} v_{\text {avg }}}{\mu}$

The mean liquid velocity is calculated with Eq. (20) [33]

$v_{\text {avg }}=\frac{Q}{\varepsilon B S}$ 
where $Q$ is the liquid volumetric flow rate $\left(\mathrm{m}^{3} \mathrm{~s}^{-1}\right), \varepsilon$ is the porosity of the volume between the electrodes (accounting for the presence or absence of the mass transfer promoter), and the product $B \cdot S$ corresponds to the cross-sectional area $\left(1.14 \times 10^{-3} \mathrm{~m}^{2}\right)$ perpendicular to the mean velocity.

\section{Results and discussion}

\subsection{Residence time distribution}

Mean detention times ( $\left.\mathrm{t}_{\text {mean }}\right)$ determined from exit age distributions $(\mathrm{E}(\theta))$ of pulse tracer tests were inversely proportional to mean velocity ( $\left.v_{\text {avg }}\right)$, as shown in Fig. 3, which is consistent with reactor theory (i.e., the theoretical detention time, $\tau$, is calculated as the volume of the reactor divided by the flow rate). Note that these mean detention times include the hydraulic entrance (from the point of tracer injection) and exit (to the point of conductivity monitoring), in addition to the reactor volume, so they are not directly comparable to the theoretical detention time of the electroactive cell volume. Generally, for a given pressure and a given average cross-flow velocity, the mean detention time decreased in the following order: small mesh, medium mesh, large mesh, and no mesh, which is consistent with increasing porosity. 


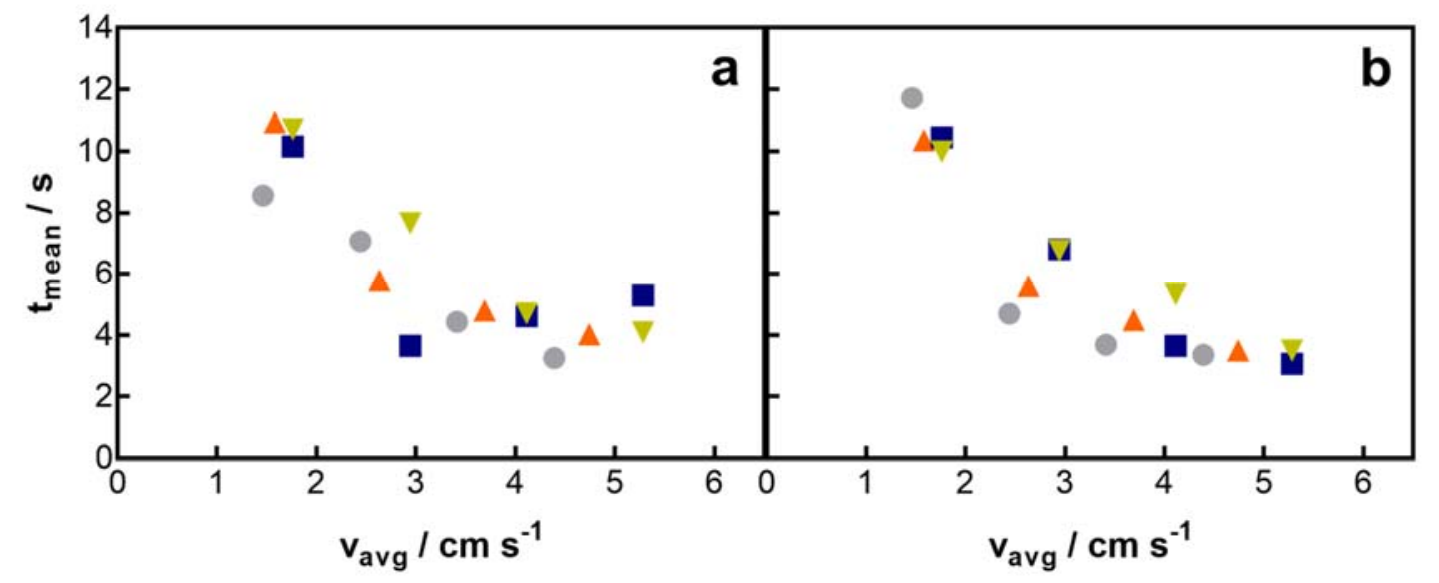

Fig. 3. Mean detention time of residence time distribution at (a) 2 bar and (b) 3 bar for different promoters: none $(\mathbf{O})$, large $(\Delta)$, medium $(\boldsymbol{\square})$, and small size $(\nabla)$.

In Fig. 4, the dimensionless dispersion number of each exit age distribution test is shown versus the average velocity of the water flow through the cell (accounting for the porosity of the mesh). The minimum, $25^{\text {th }}$ percentile, median, $75^{\text {th }}$ percentile, and maximum values of all 64 dispersion numbers (including both open and closed estimates) were $0.034,0.21,0.32,0.45$, and 3.0, respectively. For comparison, engineered disinfection reactors with dispersion numbers of $0.03,0.2$, and 1 would be considered superior, average, and poor, respectively [34]. Theoretically, with no gas flow, the dispersion number would increase with increasing liquid velocity; however, with ADE gas feed pressures of 2 bar and 3 bar, the dispersion number of the residence time distribution was not correlated with liquid velocity, mesh promoter, or ADE gas pressure (i.e., the pressure in the gas feed chamber, not the pressure inside the electrochemical cell). For each of the four mass transfer promoter conditions (none, large, medium, and small), an independent (unpaired) two-tailed unequal-variances $t$-test indicated that the mean of the eight dimensionless dispersion number values (including both open and closed dispersed flow model 
results) at an ADE gas pressure of 3 bar was not statistically different from the mean of the eight dimensionless dispersion numbers with an ADE gas pressure of 2 bar (i.e., $p>0.05$ for each of the four mesh promoters). Also, for a given ADE gas pressure, independent (unpaired) two-tailed unequal-variances $t$-tests indicated that the mean of the eight dimensionless dispersion numbers with mesh present was not statistically significantly different from the mean of the dimensionless dispersion numbers of flow through the empty cell, regardless of mesh size. 


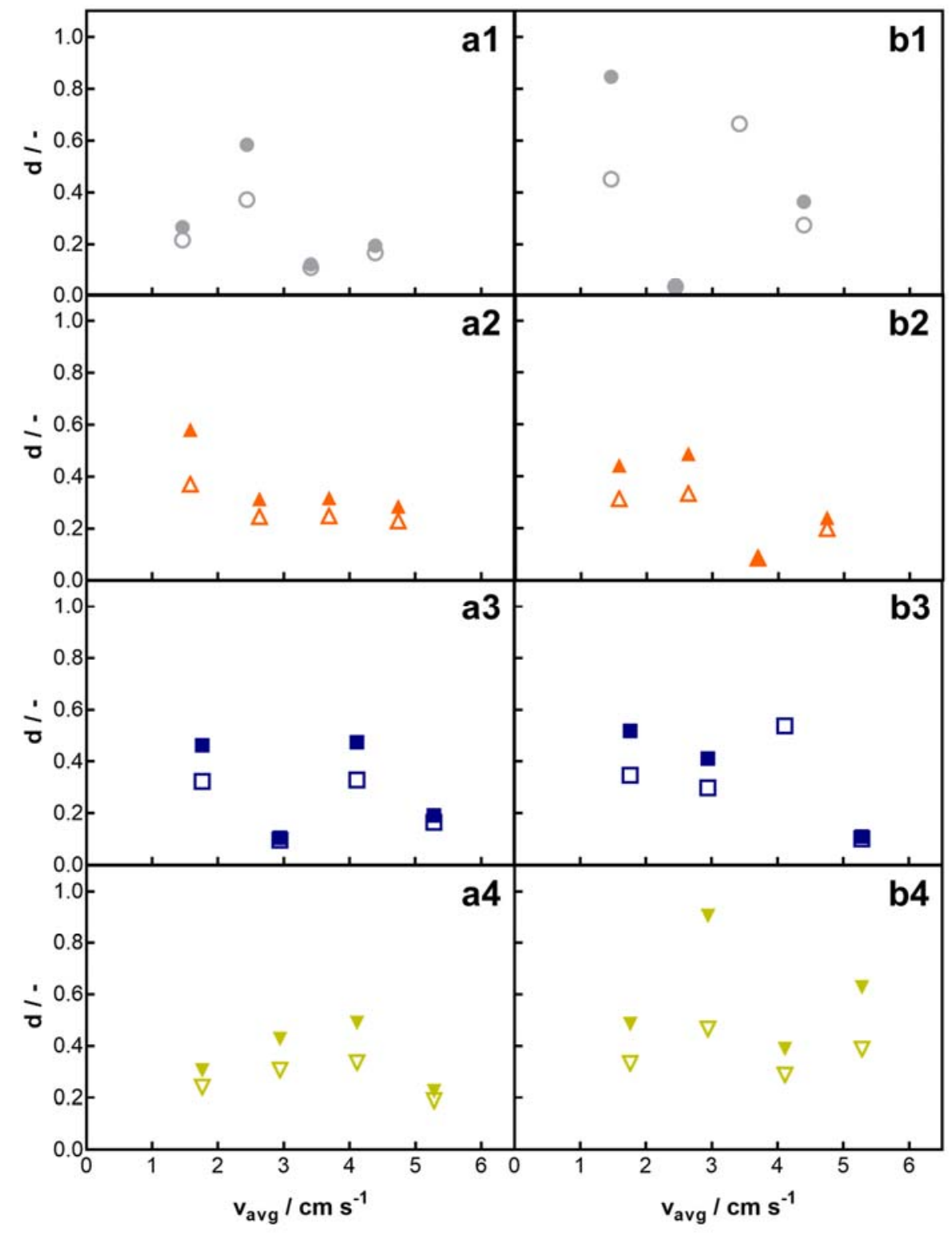

Fig. 4. Dimensionless dispersion number characterization of residence time distribution at an ADE pressure of (a) 2 bar and (b) 3 bar without (1: no mesh- $)$ and with promoters (2: large$\boldsymbol{\Delta}$, 3: medium- $\boldsymbol{\square}$, and 4: small- $\nabla$ mesh sizes) including both open and closed dispersed flow model results (open and closed symbols, respectively). 


\subsection{Mass transfer}

The experimental results of the limiting current density of the platinum sheet electrode tests are presented versus the average liquid cross-flow velocity in Fig. 5 for each of the four mesh conditions (parts a1 through a4). The corresponding Sherwood number (i.e., the dimensionless mass transfer coefficient) versus the liquid Reynolds number is shown in Fig. 5, parts b1 through b4. Both limiting current density and Sherwood number are shown in the same figure because they are two of the preferred figures of merit among electrochemists and chemical engineers; identical conclusions are drawn from the two perspectives. For 11 of the 12 limiting current density tests, the limiting current density and Sherwood number were positively correlated with average liquid cross-flow velocity and Reynolds number (except for the case of no mesh with an ADE gas feed pressure of 3 bar, which is addressed in more detail below). This positive correlation between Sherwood and Reynolds number can be predicted a priori from theoretical derivations and is well documented by many empirical investigations with various geometries (e.g., laminar flow along a flat plate, turbulent flow through a horizontal slit or a circular pipe, forced convection around a solid sphere or through a packed bed, etc.) [26,27,32,35-37]. From the linear regression of the logarithms of Sherwood number and Reynolds number expected from Eq. (18), the value of the $b$ exponent ranged from approximately 0.4 to 0.8 . The twelve $b$-values obtained are listed in Table 3. Unfortunately, these exponent values are less than one, which is consistent with most mass transfer scenarios, and that means, for a given hydraulic detention time, there are diminishing returns with respect to improving mass transfer by increasing velocity. That is, the relative increase in required flow path length (and capital cost) and head loss (and operating cost) associated with increasing the velocity is greater than the relative increase in mass transfer rate. 

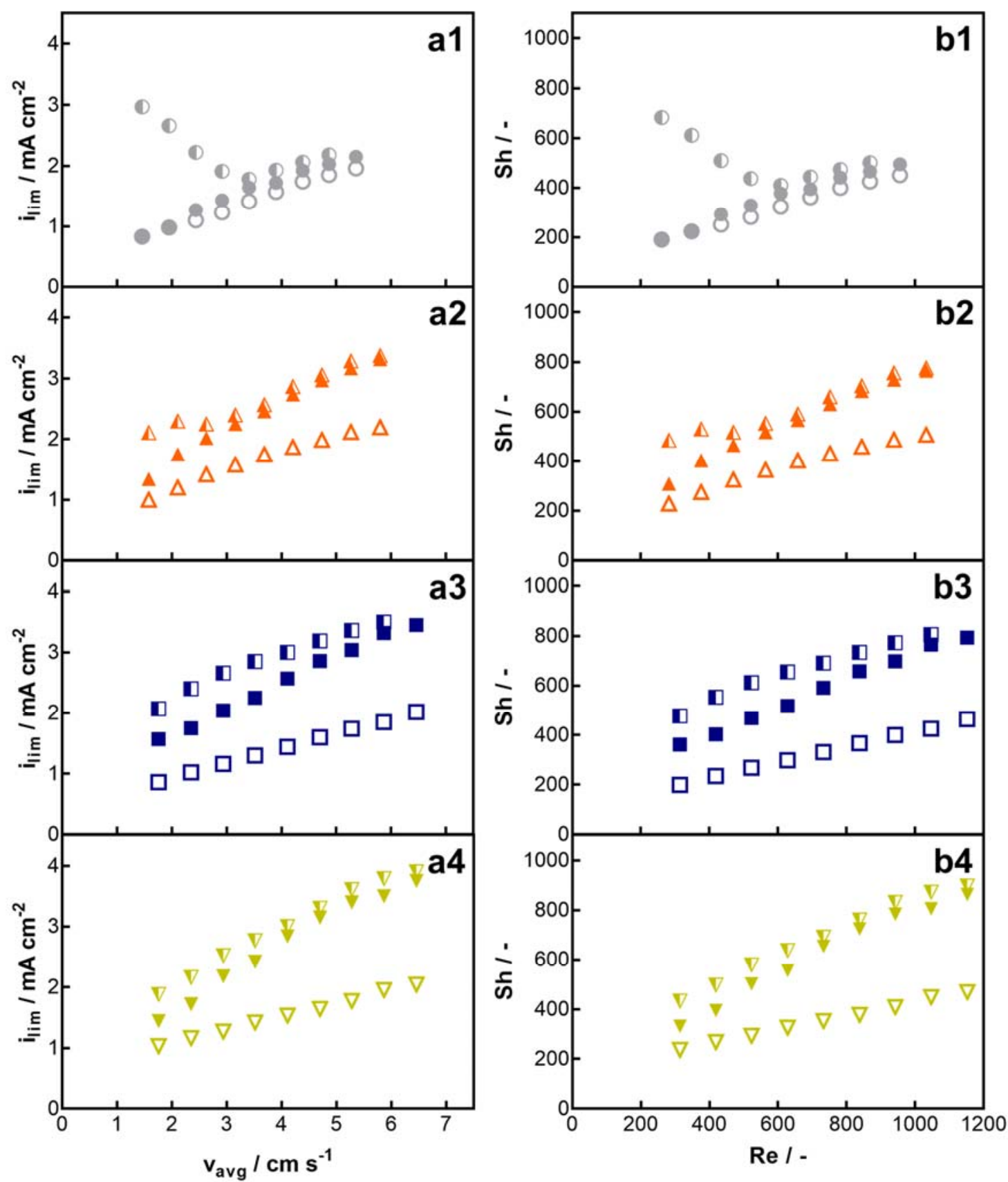

Fig. 5. Mass transfer characterization: (a) limiting current density versus mean liquid cross-flow velocity and (b) Sherwood number versus liquid Reynolds number without (1: no mesh) and with 
promoters (2: large, 3: medium, and 4: small mesh sizes) at a gas feed pressure of 0 bar (open symbol), 2 bar (closed symbol), and 3 bar (mixed symbol).

Table 3. Values of the exponent $b$ in the dimensionless mass transfer proportionality of $\mathrm{Sh} \propto \mathrm{Re}^{b}$ from Eq. (18).

\begin{tabular}{lccc}
\hline Condition & $\boldsymbol{P}_{\mathrm{ADE}}=\mathbf{0}$ bar & $\boldsymbol{P}_{\mathrm{ADE}}=2$ bar & $\boldsymbol{P}_{\mathrm{ADE}}=\mathbf{3}$ bar \\
\hline No Mesh & 0.68 & 0.76 & $0.57^{*}$ \\
Large Mesh & 0.62 & 0.68 & $0.60^{*}$ \\
Medium Mesh & 0.65 & 0.64 & 0.43 \\
Small Mesh & 0.53 & 0.76 & 0.59 \\
\hline
\end{tabular}

* For liquid $\mathrm{Re}>550$

Neither the addition of mesh without gas flow, nor the addition of gas flow without mesh, resulted in substantial improvement in mass transfer (Fig. 5). No deformation of the ADE cathode was observed. For an ADE gas pressure of zero (i.e., no gas flow), the addition of mesh (large, medium, or small) between the electrodes did not substantially increase the limiting current density or the Sherwood number, and the mean value of the four $b$ exponent values was 0.62 (with a standard deviation of samples of 0.07). When tested without mesh for a given velocity (Fig. 5a1 and 5b1), increasing the ADE gas pressure from 0 bar to 2 bar only increased the limiting current density and Sherwood number by an average of $10 \% \pm 7 \%$ (mean \pm one standard deviation). When tested with mesh but without ADE gas flow, the addition of the mesh promoters increased the limiting current density and Sherwood number by an average of $12 \% \pm$ $9 \%$. Thus, independently, neither the mesh promoters nor the gas flow substantially improved mass transfer. 
However, the combination of gas flow and mesh promoters did result in substantial improvement in mass transfer. For an $\mathrm{ADE}$ gas pressure of 2 or 3 bar, the presence of mesh significantly increased the limiting current density and Sherwood number (Fig. 5a2-a4 and 5b2b4), with average relative increases ranging from $45 \%$ to $114 \%$ (Table 4 ). It is assumed that increasing the gas pressure at (and flow through) the ADE significantly increased the mass transfer at the anode without significantly changing the dimensionless dispersion of the reactor. We suspect that the presence of the mesh increased the gas travel distance toward the platinum sheet electrode surface, which significantly enhanced the liquid-phase mass transfer efficiency.

Table 4. Average relative increase in mass transfer due to ADE gas pressure (as compared to the same mesh condition with no gas flow).

\begin{tabular}{lcc}
\hline Mesh & $\boldsymbol{P}_{\text {ADE }}=\mathbf{2}$ bar & $\boldsymbol{P}_{\text {ADE }}=\mathbf{3}$ bar \\
\hline Large Mesh & $45 \% \pm 5 \%$ & $64 \% \pm 22 \%$ \\
Medium Mesh & $76 \% \pm 4 \%$ & $114 \% \pm 20 \%$ \\
Small Mesh & $74 \% \pm 19 \%$ & $94 \% \pm 7 \%$ \\
\hline
\end{tabular}

(mean \pm one standard deviation)

With an ADE gas pressure of 3 bar (Fig. $5 \mathrm{a} 1$ and 5b1), the gas flow significantly increased mass transfer for average liquid velocity less than $3 \mathrm{~cm} \mathrm{~s}^{-1}$ and liquid Reynolds number less than 550, but with diminishing impact with increasing flow rate (likely due to the increasing hydraulic head loss). The effect of ADE gas feed pressure without mesh was further explored with additional ADE gas feed pressures, and the results (including those from Fig. 5a1 and 5b1) are shown in Fig. 6. Mass transfer effects with an ADE gas feed pressure of 1 bar were very consistent with results for 0 bar (no gas flow) and 2 bar. For ADE gas feed pressures 2.5 bar and 
greater, substantial increases in mass transfer were observed for average liquid velocity less than $3 \mathrm{~cm} \mathrm{~s}^{-1}$ and liquid Reynolds number less than 550. The average relative increases as compared to no gas flow were $90 \%, 147 \%, 213 \%, 245 \%$ for ADE gas pressures of $2.5,3.0,3.5$, and 4.0 bar, respectively. Presumably, at low liquid velocity and high ADE gas pressure, a certain fraction of the electrochemical cell volume is occupied by gas, which results in a greater liquid velocity and with the momentum of gas bubbles orthogonal to the ADE, mass transfer to the platinum sheet electrode is significantly enhanced. However, with increasing liquid velocity, the gas flow rate drops due to the increasing hydraulic head loss backpressure, and the fraction of the cell that is occupied by gas also decreases, which result in diminished mass transfer improvement.
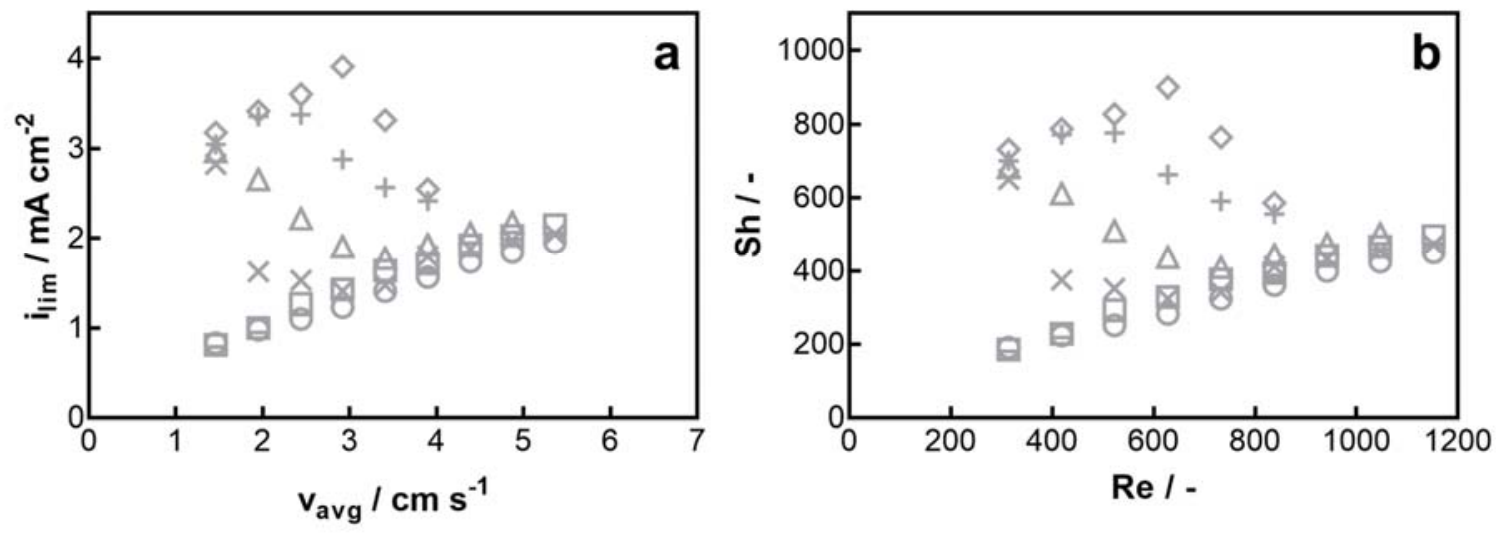

Fig. 6. Additional mass transfer characterization without promoters: (a) limiting current density versus mean liquid cross-flow velocity and (b) Sherwood number versus liquid Reynolds number at $0.0 \operatorname{bar}(\bigcirc), 1.0 \operatorname{bar}(-), 2.0 \operatorname{bar}(\square), 2.5 \operatorname{bar}(\times), 3.0$ bar $(\triangle), 3.5 \operatorname{bar}(+)$, and 4.0 bar $(\diamond)$.

Numerous correlations are found in the literature to correlate the average dimensionless mass transfer coefficient in reactors with parallel plate configuration, that is, flow in channels, with or without turbulence promoters. In Fig. 7, one can observe that the results of this work are in 
agreement with other studies in the same range of Reynolds number. In order to simplify the comparison, only select experimental data from this work are shown: condition 1: no mesh promoter and no gas flow; condition 2: medium mesh with ADE pressure of 3 bar, and condition 3: no mesh promoter with ADE pressure of 4 bar. This comparison reveals that electrochemical cells with ADE electrodes show similar trends as those described for conventional flow-by electrochemical cell configurations.

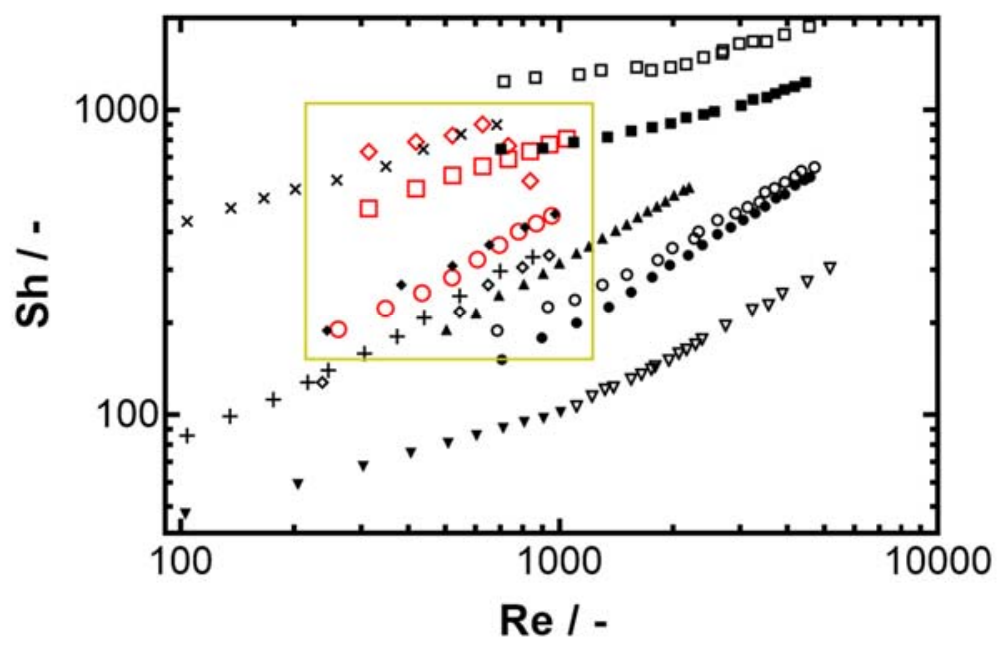

Fig. 7. Logarithmic representation of Sherwood number versus Reynolds number from experimental data from this work for no mesh promoter and no gas flow $(\bigcirc)$, medium mesh size at ADE pressure of 3.0 bar $(\square)$, and no mesh promoter with ADE pressure of at 4.0 bar $(\diamond)$. These results are compared with data from previous reports for electrochemical cells that consider rectangular flow channel cells in the presence and absence of a mesh promoter as adapted from [38]: nickel solid electrode: $(\bigcirc)$ no mesh promoter and $(\bigcirc)$ with a mesh promoter. Nanostructured nickel deposit: $(\boldsymbol{\square})$ no mesh promoter and $(\square)$ with a mesh promoter. Nickel electrode in the FM01-LC electrolyser: $(\diamond)$ no mesh promoter and $(\diamond)$ with a mesh promoter. 
Nickel electrode $(+)$ no mesh promoter and $(\times)$ with a polypropylene grid with triangular threads mesh promoter.

\section{Conclusions}

Residence time distribution and platinum-sheet electrode mass transfer effects were measured as a function of: (a) the liquid cross-flow velocity through the electrochemical cell, (b) the gas pressure of the air diffusion electrode (ADE), and (c) the presence of mass transfer promoters between the electrodes. Overall, the dispersion number of the residence time distribution was not correlated with velocity, mesh promoter, or ADE gas pressure.

The limiting current density and the corresponding dimensionless mass transfer coefficient (i.e., the Sherwood number) at the platinum sheet electrode were generally positively correlated with average liquid velocity, and for tests with no gas flow through the ADE, the Sherwood number was proportional to the Reynolds number with an exponent $b$-value of 0.62 , which means that increasing velocity yields diminishing returns in mass transfer at the electrode surface.

Independently, neither the mesh promoters nor the gas flow substantially improved mass transfer; increasing ADE gas pressure from 0 to 2 bar (without mesh) enhanced mass transfer by approximately $10 \%$, and addition of mesh promoters (without gas flow), by approximately $12 \%$. However, the combination of gas flow and mesh promoters did result in substantial increases in mass transfer. For an ADE gas pressure of 2 or 3 bar, the presence of mesh significantly increased the limiting current density and Sherwood number with average relative increases ranging from $45 \%$ to $114 \%$, as compared to the same mesh condition with no gas flow. For a given reaction efficiency, doubling the mass transfer would decrease the required reactor volume by half. 
Moreover, when the electrochemical cell was constructed without mesh promoters and operated with $\mathrm{ADE}$ gas pressures of 2.5 bar or greater, substantially greater mass transfer values (increases ranging from $90 \%$ to $245 \%$ ) were observed for liquid Reynolds number less than 550 . These results are particularly promising for the design of electrochemical cells with low capital cost and low hydraulic pumping power. For applications in which downstream gas-liquid separation is allowable, the mass transfer rate of an electrochemical reactor could be significantly improved with gas flow through one of the electrodes, resulting in a much smaller reactor (e.g., one-half to one-third of the size without the ADE).

Future work should investigate optimum mass transfer improvements as a function of both ADE gas pressure and ADE gas flow rate, which is challenging with the existing gas chamber pressure control system.

\section{Acknowledgments}

This work was partially funded by the National Science Foundation (EEC-1449500) Nanosystems Engineering Research Center on Nanotechnology-Enabled Water Treatment by MINECO (Spain) under the Project CTQ2013-48897-C2-1-R, co-financed with FEDER funds. Eliane B. Cavalcanti acknowledges the financial support from CAPES (BEX 9263/110)/MEC/Brazil, Instituto de Tecnologia e Pesquisa/ITP and Universidade Tiradentes/UNIT and Dr. Ana S. Fajardo acknowledges the European Union's Horizon 2020 research and innovation program under the Marie Sklodowska-Curie grant agreement No 843870. 


\section{References}

[1] M.A. Oturan, J.J. Aaron, Advanced oxidation processes in water/wastewater treatment: Principles and applications. A review, Crit. Rev. Environ. Sci. Technol. 44 (2014) 25772641. https://doi.org/10.1080/10643389.2013.829765.

[2] E. Brillas, C.A. Martínez-Huitle, Decontamination of wastewaters containing synthetic organic dyes by electrochemical methods. An updated review, Appl. Catal. B: Environ. 166-167 (2015) 603-643. https://doi.org/10.1016/j.apcatb.2014.11.016.

[3] F.C. Moreira, R.A.R. Boaventura, E. Brillas, V.J.P. Vilar, Electrochemical advanced oxidation processes: A review on their application to synthetic and real wastewaters, Appl. Catal. B: Environ. 202 (2017) 217-261. https://doi.org/10.1016/j.apcatb.2016.08.037.

[4] V. Poza-Nogueiras, E. Rosales, M. Pazos, M.Á. Sanromán, Current advances and trends in electro-Fenton process using heterogeneous catalysts - A review, Chemosphere 201 (2018) 399-416. https://doi.org/10.1016/j.chemosphere.2018.03.002.

[5] S.O. Ganiyu, M. Zhou, C.A. Martínez-Huitle, Heterogeneous electro-Fenton and photoelectro-Fenton processes: A critical review of fundamental principles and application for water/wastewater treatment, Appl. Catal. B: Environ. 235 (2018) 103-129. https://doi.org/10.1016/j.apcatb.2018.04.044.

[6] P. V. Nidheesh, M. Zhou, M.A. Oturan, An overview on the removal of synthetic dyes from water by electrochemical advanced oxidation processes, Chemosphere 197 (2018) 210-227. https://doi.org/10.1016/j.chemosphere.2017.12.195.

[7] E. Brillas, A review on the photoelectro-Fenton process as efficient electrochemical advanced oxidation for wastewater remediation. Treatment with UV light, sunlight, and coupling with conventional and other photo-assisted advanced technologies, Chemosphere 
250 (2020) 126198. https://doi.org/10.1016/j.chemosphere.2020.126198.

[8] E. Brillas, S. Garcia-Segura, Benchmarking recent advances and innovative technology approaches of Fenton, photo-Fenton, electro-Fenton, and related processes: A review on the relevance of phenol as model molecule, Sep. Purif. Technol. 237 (2020) 116337. https://doi.org/10.1016/j.seppur.2019.116337.

[9] S. Garcia-Segura, E.B. Cavalcanti, E. Brillas, Mineralization of the antibiotic chloramphenicol by solar photoelectro-Fenton. From stirred tank reactor to solar pre-pilot plant., Appl. Catal. $\quad$ B: $\quad$ Environ. $144 \quad$ (2014) 588-598. https://doi.org/10.1016/j.apcatb.2013.07.071.

[10] H. Olvera-Vargas, N. Oturan, M.A. Oturan, E. Brillas, Electro-Fenton and solar photoelectro-Fenton treatments of the pharmaceutical ranitidine in pre-pilot flow plant $\begin{array}{llllll}\text { scale, } & \text { Sep. } & \text { Purif. } & \text { Technol. } & 146 & \text { (2015) }\end{array}$ https://doi.org/10.1016/j.seppur.2015.03.046.

[11] M.P. Rosa Barbosa, N.S. Lima, D.B. de Matos, R.J. Alves Felisardo, G.N. Santos, G.R. Salazar-Banda, E.B. Cavalcanti, Degradation of pesticide mixture by electro-Fenton in filter-press reactor, J. Water Process Eng. $25 \quad$ (2018) 222-235. https://doi.org/10.1016/j.jwpe.2018.08.008.

[12] A.S. Fajardo, A.J. dos Santos, E.C.T. de Araújo Costa, D.R. da Silva, C.A. MartínezHuitle, Effect of anodic materials on solar photoelectro-Fenton process using a diazo dye as a model contaminant, Chemosphere $225 \quad$ (2019) 880-889. https://doi.org/10.1016/j.chemosphere.2019.03.071.

[13] Q. Zhang, M. Zhou, G. Ren, Y. Li, Y. Li, X. Du, Highly efficient electrosynthesis of hydrogen peroxide on a superhydrophobic three-phase interface by natural air diffusion, 
Nat. Commun. 11 (2020) 1-11. https://doi.org/10.1038/s41467-020-15597-y.

[14] C.M. Dominguez, N. Oturan, A. Romero, A. Santos, M.A. Oturan, Removal of lindane wastes by advanced electrochemical oxidation, Chemosphere 202 (2018) 400-409. https://doi.org/10.1016/j.chemosphere.2018.03.124.

[15] E. Mousset, Y. Pechaud, N. Oturan, M.A. Oturan, Charge transfer/mass transport competition in advanced hybrid electrocatalytic wastewater treatment: Development of a new current efficiency relation, Appl. Catal. B: Environ. 240 (2019) 102-111. https://doi.org/10.1016/j.apcatb.2018.08.055.

[16] S. Cotillas, J. Llanos, M.A. Rodrigo, P. Cañizares, Use of carbon felt cathodes for the electrochemical reclamation of urban treated wastewaters, Appl. Catal. B: Environ. 162 (2015) 252-259. https://doi.org/10.1016/j.apcatb.2014.07.004.

[17] J. Paramo-Vargas, A.M.E. Camargo, S. Gutierrez-Granados, L.A. Godinez, J.M. PeraltaHernandez, Applying electro-Fenton process as an alternative to a slaughterhouse effluent $\begin{array}{llllll}\text { treatment, } & \text { J. } & \text { Electroanal. } & \text { Chem. } & 754 & \text { (2015) }\end{array}$ https://doi.org/10.1016/j.jelechem.2015.07.002.

[18] K. V. Plakas, S.D. Sklari, D.A. Yiankakis, G.T. Sideropoulos, V.T. Zaspalis, A.J. Karabelas, Removal of organic micropollutants from drinking water by a novel electroFenton filter: Pilot-scale studies, Water Res. $91 \quad$ (2016) 183-194. https://doi.org/10.1016/j.watres.2016.01.013.

[19] L. Liang, F. Yu, Y. An, M. Liu, M. Zhou, Preparation of transition metal composite graphite felt cathode for efficient heterogeneous electro-Fenton process, Environ. Sci. Pollut. Res. 24 (2017) 1122-1132. https://doi.org/10.1007/s11356-016-7389-3.

[20] S.Z.J. Zaidi, F.C. Walsh, C. Harito, Mass transport control of oxygen reduction at graphite 
felt with subsequent decolourisation of RB-5 dye in a parallel plate flow reactor, J. Taiwan Inst. Chem. Eng. 104 (2019) 123-129. https://doi.org/10.1016/j.jtice.2019.08.020.

[21] W. Yang, M. Zhou, N. Oturan, Y. Li, M.A. Oturan, Electrocatalytic destruction of pharmaceutical imatinib by electro-Fenton process with graphene-based cathode, Electrochim. Acta 305 (2019) 285-294. https://doi.org/10.1016/j.electacta.2019.03.067.

[22] C. Lizama-Bahena, A. Álvarez-Gallegos, J.A. Hernandez, S. Silva-Martinez, Elimination of bio-refractory chlorinated herbicides like atrazine, alachlor, and chlorbromuron from aqueous effluents by Fenton, electro-Fenton, and peroxi-coagulation methods, Desalin. Water Treat. 55 (2015) 3683-3693. https://doi.org/10.1080/19443994.2014.939858.

[23] S. Ellouze, S. Kessemtini, D. Clematis, G. Cerisola, M. Panizza, S.C. Elaoud, Application of Doehlert design to the electro-Fenton treatment of Bismarck Brown Y, J. Electroanal. Chem. 799 (2017) 34-39. https://doi.org/10.1016/j.jelechem.2017.05.042.

[24] A. Cruz-Rizo, S. Gutiérrez-Granados, R. Salazar, J.M. Peralta-Hernández, Application of electro-Fenton/BDD process for treating tannery wastewaters with industrial dyes, Sep. Purif. Technol. 172 (2017) 296-302. https://doi.org/10.1016/j.seppur.2016.08.029.

[25] E. Brillas, A. Thiam, S. Garcia-Segura, Incineration of acidic aqueous solutions of dopamine by electrochemical advanced oxidation processes with Pt and BDD anodes, J. Electroanal. Chem. 775 (2016) 189-197. https://doi.org/10.1016/j.jelechem.2016.04.054.

[26] M.M. Benjamin, D.F. Lawler, Water Quality Engineering, Wiley, 2013.

[27] J.C. Crittenden, R.R. Trussell, D.W. Hand, K.J. Howe, MWH's Water Treatment: Principles and Design, 3rd ed., Wiley, 2012.

[28] P. V. Danckwerts, Continuous flow systems. Distribution of residence times, Chem. Eng. Sci. 50 (1995) 3855. https://doi.org/10.1016/0009-2509(96)81810-0. 
[29] E.P. Rivero, F.F. Rivera, M.R. Cruz-Díaz, E. Mayen, I. González, Numerical simulation of mass transport in a filter press type electrochemical reactor FM01-LC: Comparison of predicted and experimental mass transfer coefficient, Chem. Eng. Res. Des. 90 (2012) 1969-1978. https://doi.org/10.1016/j.cherd.2012.04.010.

[30] P.R.F. da Costa, E.C.T. de A. Costa, S.S.L. Castro, C.A. Martínez-Huitle, A.S. Fajardo, Cashew-Nut effluent: An anodic oxidation treatment using a batch recirculation reactor with BDD anode, J. Electrochem. Soc. $165 \quad$ (2018) E659-E664. https://doi.org/10.1149/2.0121813jes.

[31] C. Ponce-de-León, G.W. Reade, I. Whyte, S.E. Male, F.C. Walsh, Characterization of the reaction environment in a filter-press redox flow reactor, Electrochim. Acta 52 (2007) 5815-5823. https://doi.org/10.1016/j.electacta.2007.02.080.

[32] R.B. Bird, W.E. Steward, E.N. Lightfoot, Transport Phenomena, 2nd ed., Wiley, 2007.

[33] F.F. Rivera, M.R. Cruz-Díaz, E.P. Rivero, I. González, Analysis and interpretation of residence time distribution experimental curves in FM01-LC reactor using axial dispersion and plug dispersion exchange models with closed-closed boundary conditions, Electrochim. Acta 56 (2010) 361-371. https://doi.org/10.1016/j.electacta.2010.08.069.

[34] M. Davis, Water and Wastewater Engineering: Design Principles and Practice, 2nd editio, McGraw Hill, New York, Chicago, San Francisco, Athens, London, Madrid, Mexico City, Milan, New Delhi, Singapore, Sydney, Toronto, 2020.

[35] E.L. Cussler, Mass transfer in fluid systems, Cambridge University Press, 1984.

[36] H. Xu, W. Huang, Y. Xing, H. Lin, H. Ji, M. Jiang, X. Liu, S. Gan, Effect of Configuration on Mass Transfer in a Filter-press Type Electrochemical Cell, Chinese J. Chem. Eng. 16 (2008) 198-202. https://doi.org/10.1016/s1004-9541(08)60062-2. 
[37] A.N. Colli, R. Toelzer, M.E.H. Bergmann, J.M. Bisang, Mass-transfer studies in an electrochemical reactor with a small interelectrode gap, Electrochim. Acta 100 (2013) 7884. https://doi.org/10.1016/j.electacta.2013.03.134.

[38] F.J. Recio, P. Herrasti, L. Vazquez, C. Ponce De León, F.C. Walsh, Mass transfer to a nanostructured nickel electrodeposit of high surface area in a rectangular flow channel, Electrochim. Acta 90 (2013) 507-513. https://doi.org/10.1016/j.electacta.2012.11.135.

[39] C. Rodrigues, V. Geraldes, M.N. de Pinho, V. Semião, Mass-transfer entrance effects in narrow rectangular channels with ribbed walls or mesh-type spacers, Chem. Eng. Sci. 78 (2012) 38-45. https://doi.org/10.1016/j.ces.2012.04.023. 